\section{Monopotassium Phosphate for Olive Fruit Abscission}

\author{
Diego Barranco \\ Departamento de Agronomía, ETSIAM, Universidad de Córdoba, Apdo. 3048, \\ Córdoba, Spain
}

Octavio Arquero and Carlos Navarro

Departamento de Olivicultura, CIFA Alameda del Obispo, Junta de Andalucía, Apdo. 4240, Córdoba, Spain

\section{Hava F. Rapoport \\ Instituto de Agricultura Sostenible, CSIC, Apdo. 4084, Córdoba, Spain}

Additional index words. mechanical harvest, Olea europaea, $\mathrm{PO}_{4} \mathrm{H}_{2} \mathrm{~K}$, ethephon

World olive production covers $9.5 \times 10^{6}$ ha and yields $\approx 2.5 \times 10^{6}$ t of olive oil and $1.25 \times$ $10^{6} \mathrm{t}$ of table olives annually (IOOC, 2002). For both oil and table production, harvest represents a critical expense to the farmer, costing as much as $50 \%$ of total crop value. Particular difficulties are encountered in the case of immature green fruits, harvested for table olives or to obtain high-quality oil, where the efficiency of mechanical harvesting by trunk vibration is particularly low due to high fruit retention force and small fruit size.

The use of chemicals to loosen fruit in olive has been under investigation for over 35 years (Hartmann et al., 1970). The best of the chemical looseners have been the ethylene-releasing compounds, but, when used effectively for fruit abscission, they can also cause excessive leaf loss (Martin et al., 1981). Laboratory tests by Banno et al. (1993) showed the effectiveness of phosphorous-containing compounds as abscission agents, and that foliar applied $\mathrm{NaH}_{2} \mathrm{PO}_{4}$ caused fruit abscission with minimal leaf loss. Monopotassium phosphate $\mathrm{KH}_{2} \mathrm{PO}_{4}(\mathrm{MKP})$ is an economical and readily accessible fertilizer which is applied as a foliar spray to olive trees, which furthermore has none of the negative affects associated with sodium-containing compounds. We report here the effect of foliar-applied MKP, alone or in association with an ethylene releaser, on olive fruit abscission under field conditions.

Experiments were performed in 2000 with 'Arbequina' and in 2001 with 'Picual', both important cultivars for oil production. For 'Arbequina', difficult harvesting has been associated with low weight of the small fruit. 'Picual' has larger fruit, which characteristically have lower fruit retention force (Barranco and Rallo, 2000). In both experiments, 27 uniform, highly producing trees were used, 20 years old in the case of 'Arbequina' and 25 years old for 'Picual', grown under irrigation at the CIFA (Agricultural Research and Development Institute) experiment station of Córdoba, Spain.

Treatments and experimental design were the same for both years. Three treatments were

Received for publication 23 Apr. 2003. Accepted for publication 28 Jan. 2004. applied: 1) control, untreated; 2) 3\% aqueous MKP (MKP 3\%); and 3) 3\% aqueous MKP plus $0.05 \%$ ethephon, an ethylene-releasing product (MKP 3\%+Et). A randomized block design was used with nine blocks and three treatments, one tree per block. The trees were sprayed with $8 \mathrm{~L}$ of solution until drops were noted on the leaves. Treatment was 9 Nov. 2000 for 'Arbequina, and 29 Nov. 2001 for 'Picual'. The fruit retention force (FRF) for 50 fruit per tree was measured once or twice weekly with a dinamometer (Correx, Switzerland) for 6 weeks. Leaf abscission was estimated by observation of leaves on the ground below the tree canopy following product application and at harvest.

At $15 \mathrm{~d}$ after treatment, mechanical harvest consisting of a 6-s trunk vibration per tree was carried out for six trees per treatment. The fruit that remained on the tree were harvested manually, and efficiency of mechanical harvest was calculated as percentage fruit weight (mechanically harvested fruit weight $\times 100 /$ total harvested fruit weight). On the remaining three unharvested trees per treatment, FRF measurements were continued until 6 weeks after treatment application. Analyses of variance were performed on the data from each experiment.

For 'Arbequina' (Fig. 1), FRF was reduced with application of both MKP 3\% and MKP $3 \%+$ Et. The greater reduction was obtained with MKP $3 \%+E t$, which differed significantly from the two other treatments from 4 to $28 \mathrm{~d}$

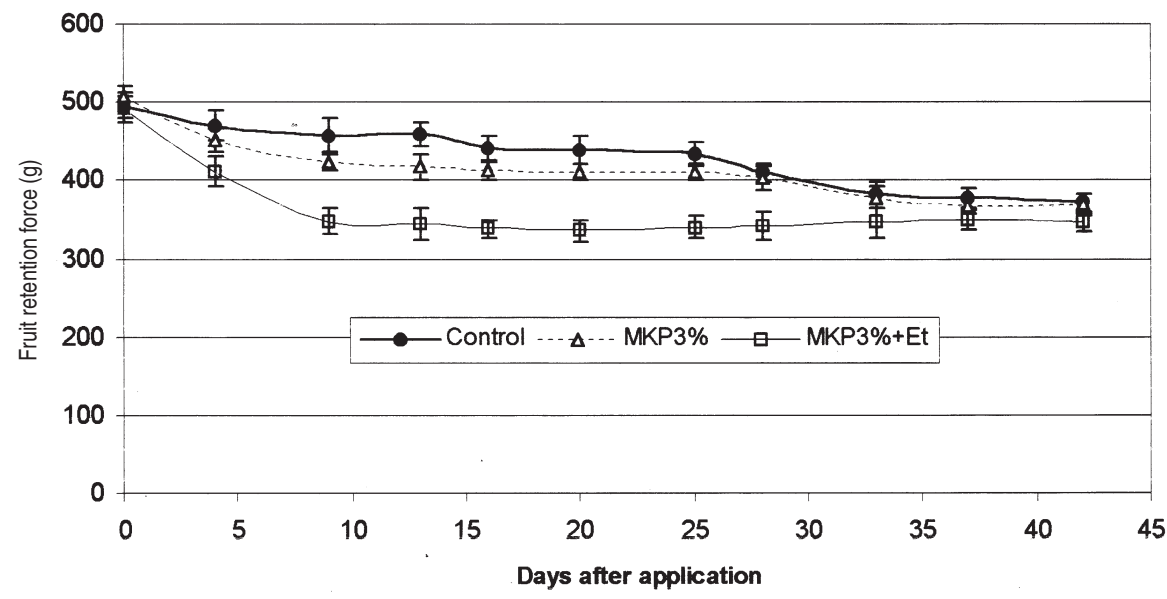

Fig. 1. Timecourse of FRF (fruit retention force) in 'Arbequina' olives. For the first four dates, until $15 \mathrm{~d}$ after application, each point is the mean value for 9 trees per treatment ( 50 fruit per tree); after that time the mean values are for 3 trees per treatment. Treatment applied 9 Nov. 2000.

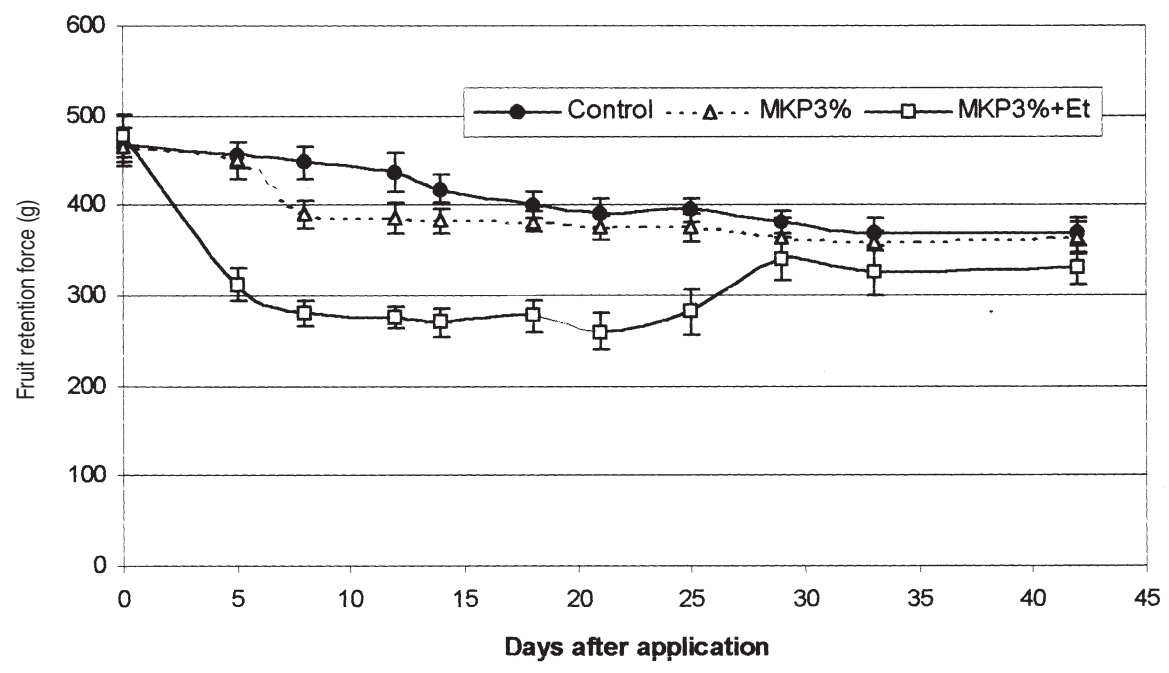

Fig. 2. Timecourse of FRF (fruit retention force) in 'Picual' olives. For the first four dates, until 15 days after application, each point is the mean value for 9 trees per treatment (50 fruit per tree); after that time the mean values are for 3 trees per treatment. Treatment applied 29 Nov. 2001. 
Table 1 . Mechanical harvest efficiency $\%$ (mechanically harvested fruit weight $\times 100 /$ total harvested fruit weight) for 'Arbequina' and 'Picual' olives.

\begin{tabular}{lccc}
\hline Experiment & Control & MKP3\% & MKP3\%+E \\
\hline 'Arbequina'(2000) & $45.6 \mathrm{a}^{\mathrm{z}}$ & $60.9 \mathrm{~b}$ & $61.1 \mathrm{~b}$ \\
'Picual' (2001) & $83.5 \mathrm{a}$ & $87.2 \mathrm{ab}$ & $94.2 \mathrm{~b}$ \\
\hline
\end{tabular}

${ }^{2}$ Mean separation within file by Duncan's multiple range test, $P<0.05$.

after treatment. The FRF for MKP 3\% was reduced less, but was significantly lower than that of the control until $25 \mathrm{~d}$ after application, when control FRF also dropped (Fig. 1). For 'Picual' (Fig. 2), the timing and pattern of the effect of the different treatments on FRF were quite similar to that for 'Arbequina'. Application of MKP3\% alone reduced FRF significantly with respect to the control by $8 \mathrm{~d}$ after treatment. The difference between those treatments was maintained until 18 d, when FRF in the control also dropped. The FRF was reduced even further with the application of MKP3\%+Et, an effect that was apparent at $5 \mathrm{~d}$ after treatment and lasted until $25 \mathrm{~d}$ (Fig. 2).

Mechanical harvest efficiency is presented in Table 1. For 'Arbequina', treatment with both MKP3\% and MKP3\%+Et significantly increased the harvest efficiency as compared to the control, although the difference between the two products was not significant. For 'Picual', the mechanical harvest efficiency was greater than in 'Arbequina' possibly due to the much lower FRF and larger fruit size of 'Picual'. Still, a significant increase in mechanical harvest efficiency was observed for the trees treated with MKP3\%+Et over those of the control. No significant leaf drop was observed in any of the treatments either before or at harvest.

Monopotassium phosphate is an economical fertilizer that, when applied in $3 \%$ solutions, reduced the fruit retention force in olive while improving mechanical harvest. The incorporation of small amounts (500 ppm) of Etephon caused greater FRF reduction and improved mechanical harvest efficiency without causing leaf drop. For the early harvest required for quality oil production, a foliar spray of MKP $15 \mathrm{~d}$ before mechanical harvest can reduce the high FRF of the immature fruit and facilitate fruit loosening.

\section{Literature Cited}

Banno, K., G.C. Martin, and R.M. Carlson. 1993. The role of phosphorus as an olive leaf and fruitabscission inducing agent. J. Amer. Soc. Hort. Sci. 118(5):599-604.

Barranco, D. and L. Rallo. 2000. Olive cultivars in Spain. HortTechnology 10(1):7-10.

International Olive Oil Council. 2002. Statistical data of production of olive oil and table olives. Olivae 94:32-33.

Hartmann, H.T., A. Tombesi, and J. Whisler. 1970. Promotion of ethylene evolution and fruit abscission in the olive by 2-chloroethanephosphonic acid and cycloheximide. J. Amer. Soc. Hort. Sci. 95:635-640.

Martin, G.C., S. Lavee, and G.S. Sibbet. 1981. Chemical loosening agents to assist mechanical harvest of olive. J. Amer. Soc. Hort. Sci. 106:325-330 